\title{
HISTORIAS DE TRÁNSITOS Y TRANSGRESIONES DEL GÉNERO EN EL ARMARIO DE ORLANDO DE VIRGINIA WOOLF
}

\author{
Mélida Paola Frye Córdoba \\ José Ismael Gutiérrez.
}

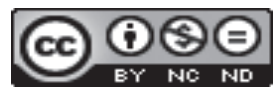

Esta obra está bajo una licencia Creative Commons

Reconocimiento-No Comercial-Sin Obra Derivada 



\title{
HISTORIAS DE TRÁNSITOS Y TRANSGRESIONES DEL GÉNERO EN EL ARMARIO DE ORLANDO DE VIRGINIA WOOLF
}

\author{
STORIES OF TRANSITS AND TRANSGRESSIONS OF GENRE IN \\ THE CLOSET OF ORLANDO BY VIRGINIA WOOLF
}

\author{
Mélida Paola Frye Córdoba \\ José Ismael Gutiérrez.
}

\begin{abstract}
RESUMEN
El presente artículo de reflexión analiza la novela Orlando, publicada por Virginia Woolf en 1928. Esta obra se estudia como un texto crítico-reflexivo frente a temas como el género, los trajes, la moda y los estereotipos de género. Es por ello que se analizan los episodios clave de la obra en los cuales su protagonista transgrede convenciones sociales a través de los trajes hasta los momentos del travestismo. De igual forma se estudia la incidencia de estos cambios de trajes, de rol social y de género como transgresiones a la normatividad.

Palabras clave: Orlando, trajes, moda, género, travestismo.
\end{abstract}

\begin{abstract}
This thesis is an analysis of the novel Orlando, published by Virginia Woolf in 1928. This work is studied as a critical-reflexive text, involving issues of gender, clothing, fashion and gender stereotypes. For this purpose, key parts of the novel in which the protagonist transgresses social conventions through specific uses of clothing, including transvestism, are studied. Likewise, the incidence of these changes of clothing, that are also changes of social and gender role, are studied as transgressions to the normativity.

Key words: Orlando, clothing, fashion, gender, transvestism.
\end{abstract}

\section{Introducción}

Orlando es una obra literaria que, en el interior de su relato, guarda un ropero abarrotado de secretos, misterios, intrigas, guiños irónicos, críticas y reflexiones. Abrir las compuertas

\footnotetext{
M.L. Mélida Paola Frye Córdoba. Universidad de Las Palmas de Gran Canaria. Investigadora. Escuela de Doctorado. España.

Correo electrónico: melida.frye@alu.ulpgc.es

Dr. José Ismael Gutiérrez. Universidad de Las Palmas de Gran Canaria. Profesor titular. Departamento de Filología Española, Clásica y Árabe. España.

Correo electrónico: joseismael.gutierrez@ulpgc.es
}

Recepción: 13- 05- 2016

Aceptación: 31- 08- 2016 
de este armario implica toparse con episodios diversos de trajes y travestismos que, en los heterogéneos momentos históricos en que se ambientan (desde el siglo XVI hasta principios del XX), rompen con los convencionalismos. De entrada, incursionar en ese guardarropa de la novela presupone tener que enfrentarse a preguntas que desajustan los cánones del sujeto normalizado, indagaciones del tipo: ¿de qué manera Orlando es condicionado/a según sus roles sociales y de género? ¿Cómo se resiste Orlando a ser encasillado/a, según los estereotipos de género, en una identidad estática y rigurosa?

Orlando es una obra escrita por Virginia Woolf (1882-1941) a finales de la segunda década del siglo pasado, cuando sobrepasaba ya los cuarenta años. Basada libremente en algunos pasajes de la vida de Vita Sackville-West -la amante de Woolf entre 1922 y 1927, año en que su amiga la traiciona al encapricharse con Mary Campbell-, la novela se compone de seis capítulos referidos en un tono burlón por la voz de un "biógrafo" ficticio. Porque el texto, aun cuando pretenda garantizar el efecto de verosimilitud apelando a documentos históricos y archivos supuestamente consultados, es una falsa biografía, un artefacto de la imaginación mediante el que se parodia la tradición que del género biográfico existía ya en el periodo victoriano en Inglaterra, donde predominaba la autoría masculina y donde la mayor parte de los personajes biografiados eran varones. ${ }^{1} \mathrm{Al}$ mismo tiempo, constituye un monumento de venganza contra la mujer que la había abandonado (McNamara, 2011, párrs. 2-4, 19). ${ }^{2}$

Pese a no ser concebido por la autora como uno de sus proyectos más serios (Cfr. Woolf, 1980, pp. 119-20), la novela, que resultó ser uno de sus mayores éxitos literarios, presenta la posibilidad de indagar en cuestiones como la de los trajes o la de las identidades femenina y masculina a partir de las vestimentas que los personajes utilizan. En ella el/la protagonista atraviesa varios siglos viviendo en posiciones sociales diversas, cambiando tanto de sexo como de género, con los subsiguientes problemas de identidad que esas alteraciones conllevan.

Orlando ha sido una de las creaciones más estudiadas de Woolf. Desde su aparición en 1928, ha sido objeto de diversos acercamientos críticos relacionados con los roles de género, sobre todo desde la década del 70 en adelante, y con su variación a lo largo de la historia (Cfr. Marcus, 1987; Caughie, 1989; Roe, 1990; Cervetti, 1996; Sánchez-Pardo González, 2004; Gans, 2011). Es normal que una novela que cuestiona la validez de las diferencias teóricas entre hombres y mujeres haya propiciado enfoques de esta naturaleza. Así, muy comúnmente se ha vislumbrado en ella una propuesta que, adelantándose a algunos postulados del posfeminismo contemporáneo, apuesta en el ámbito de la ficción por el modelo humano andrógino, e incluso por la práctica bisexual, como paradigmas alternativos y viables para la mujer de hoy en día, gracias a los cuales esta podría trascender el secular antagonismo que subyace a la polaridad, culturalmente inamovible, de lo "masculino" y lo "femenino" (Cfr. Bazin, 1973; Farwell, 1975; Schowalter, 1977a; Gascón-Vera, 2002; Diego y Vázquez, 2002a). Orlando efectúa un recorrido transexual y transgenérico en un perímetro transtemporal dilatado. En este sentido, la androginia conceptual y práctica que vendría a demandar el texto se erigiría no solo en una forma de vida que prefigura narrativamente el estado más democratizador e igualitario del hombre - de la mujer- posmoderno, sino que ella misma sugiere también una metáfora del proceso creador, tradicionalmente gestionado solo por varones, en el que las fisuras que separan a ambos sexos pueden muy bien neutralizarse.

La disolución de los binarismos genéricos en Orlando ha suscitado igualmente el cotejo de ciertas secuencias narrativas y la construcción sociopolítica y cultural de la homosexualidad y del deseo lesbiano durante el periodo posvictoriano (Sanyal, 2014). No obstante, aunque, 
como ha precisado Gascón-Vera y otras investigadoras, Orlando reivindique "la posibilidad de un proyecto vital nuevo en donde el sujeto se desliza por distintas identidades sexuales literarias e históricas destruyendo los limites ontológicos para destrozar las clasificaciones rígidas y las polaridades fijas que prescriben unas normativas diferenciales entre los sexos" (2002, p. 106), sorprende que no se haya profundizado en demasía en la importancia que tiene el vestuario, en tanto factor determinante de comportamientos y de funciones para hombres y mujeres, ni tan siquiera en el papel del travestismo femenino en la novela. Una tentativa que no está libre de perfiles subversivos, pese a que, tal como ha evidenciado semejante praxis a lo largo del tiempo, la apropiación de ropas varoniles por parte de la mujer no ha supuesto un fenómeno tan estigmatizado como la del hombre que se ha investido de prendas femeninas, dado que en nuestra civilización, dominada por valores falocéntricos, lo masculino es el término marcado en la tradicional dualidad de los sexos (Cfr. Gutiérrez, 2013, p. 36). En vista de todo ello, la causa que nos ha impulsado a realizar el presente trabajo no resulta ociosa. Además, sin aspirar a ser pionero en la materia, intentamos en él una mejor conceptualización de esta faceta prioritaria en la obra de Virginia Woolf.

El núcleo que ha promovido nuestra revisión de esta obra gira, pues, alrededor de la problematización operada en el tratamiento de las normas y de los roles de género con la firme intención de desestabilizar los estereotipos sociales y sexuales preconstruidos. En el personaje de Orlando, además de darse un trastocamiento de índole fisiológica, es decir, aparte de encontramos ante un hombre que se acuesta como tal y que, tras experimentar un cambio de sexo espontáneo, se despierta luego como mujer, se atisba el delineamiento de un ser complejo que transita por diversas clases sociales y que muta de género a través de trajes y de prendas que incluyen prácticas transgresoras como el travestismo, mediante las que se exploran y se entrecruzan las fronteras de lo genérico y de lo clasificatorio.

\section{Algunos elementos conceptuales}

A lo largo de la historia, las diferencias de género han venido demarcadas por la hegemonía de ciertos estereotipos culturales que se materializan en la forma de vestir y de representar una presencia corporal determinada ante una sociedad que ha legitimado siempre las conductas consideradas normales, al tiempo que ha rechazado las que estima como anómalas, espurias.

A priori, el traje, en tanto marcador de ambos sexos, está atravesado por presupuestos históricos y por los convencionalismos de la sociedad. La moda es definida por Entwistle como "un sistema particular de vestir que se encuentra bajo determinadas circunstancias sociales" (2002, p. 56). La moda exhibe arrogantes prendas de alto costo, símbolo de estatus social y riqueza. Antes del siglo XX, el burgués que tenía poder económico podía vestirse a la moda, hecho que ratificaba su nivel adquisitivo: "En Europa los ricos a partir de 1700 operaban modas a un grupo de clase alta que significaban lujo y castidad y profusión" (Cruz de Amenábar, 1996, p. 32). Los mercaderes y comerciantes no les permitían a los campesinos participar demasiado de este fenómeno. Por esta razón los granjeros usaban trajes humildes contrarios a la exuberancia de las clases altas y adineradas de Inglaterra (Entwistle, 2002, p. 102). Legitimada por el poder económico, la moda se distingue porque la materia prima, los diseños y la comercialización de la vestimenta son de tan alto coste que solo podía involucrarse en este proceso quien tuviese el suficiente dinero para producir y adquirir dichos artículos. Con todo, se impone aclarar un hecho: el surgimiento de la moda no principia con el 
ascenso de la burguesía, sino que sus inicios se hallan mucho más atrás. Son la monarquía y la nobleza, incluso el clero, estamentos de origen medieval, las que, en primer lugar, empiezan a interesarse por el atuendo como un síntoma de distinción, de rango y coquetería:

\footnotetext{
[...] en las etapas anteriores a la moda burguesa predominaban en Europa las elites aristocráticas que controlaban formalmente el privilegio del vestir. Mediante el dictado de los Leyes Suntuarias se prohibía el uso de determinadas ropas, telas y/o colores a todos aquellos que no pertenecieran a las cortes, a la nobleza y al clero, por ejemplo. Este sistema del vestir respondía a sociedades cuyas estructuras internas se caracterizaban por la fijeza de los roles sociales (Zambrini, 2009, párr. 6)
}

Cuestión complementaria a la jerarquización social de la moda, es lo imbuido que están los usos vestimentarios del paradigma de género. Según Elizabeth Wilson, la moda aparece "obsesionada con el género [...], está siempre trabajando y rehaciendo la barrera del género" (cit. en Entwistle, 2002, p. 64); por ende, cualquier valoración del vestir no puede dejar a un lado el reconocimiento del género (Entwistle, 2002, p. 64). Y es que los trajes comunican, a través de la imagen que proyectan, los cuerpos vestidos, los cuales diferencian el género de quien los viste, determinando, desde la apariencia, si se es mujer u hombre. La moda tiene género y se representa mediante las prendas llamadas femeninas y masculinas hechas para la instrumentalización de mujeres y hombres en cada época y sociedad. El vestido cumple, por tanto, una función fundamental, definiendo cánones de feminidad y masculinidad históricamente establecidos; incluso llega a regir moldes estereotipados impuestos en algunos periodos históricos. El cuerpo vestido se inserta así en una taxonomía de género y de rol social.

Según Marcel Mauss, el modo en que hombres y mujeres llegan a usar sus cuerpos es diferente, puesto que las técnicas corporales tienen género. Varones y hembras aprenden a caminar, a hablar, a correr, a luchar de forma distinta. Además, aunque el antropólogo y sociólogo francés se detenga poco en la cuestión de la indumentaria, no pasa por alto el detalle de que las mujeres aprenden a andar con tacones, habilidad para la que se requiere de un entrenamiento que, como consecuencia de la mencionada socialización, no suele desarrollarlo la mayoría de los hombres (cit. en Entwistle, 2002, p. 20).

La ropa y el traje desempeñan el rol de categorizar el cuerpo sexuado; "llaman la atención hacia las diferencias entre los hombres y las mujeres, que de otro modo podrían estar ocultas" (Entwistle, 2002, p. 162). La indefinición genera desorden, mientras que lo bien delimitado anula cualquier conflicto de reconocimiento. La ropa fragmenta las "condiciones" y las creencias culturales de lo que es posible, "normal", "real" y "verdadero". La moda suscita un sentido de pertenencia frente a una comunidad que puede ser mayoritaria o minoritaria, según las prendas y accesorios que se empleen, componentes que exhiben y declaran el estatus, el sexo, el género, la raza, la clase social y, por supuesto, el nivel económico de sus portadores o portadoras. Este modelo divisorio es inculcado al ser humano desde antes de que empiece a razonar, imprimiéndose ya la asunción de un cierto estereotipo en las costumbres cotidianas del niño o de la niña.

En 1922, pocos años antes de que Woolf se propusiera escribir Orlando, la palabra "estereotipo" denotaba un "proceso de impresión, se adopt[aba] metafóricamente como un concepto de ciencias sociales para explicar cómo las personas poseen pre-conceptos sobre otras, tan solo como si fuesen reimpresiones de un molde" (Lippmann, 1964, p. 81). Este concepto permitirá estudiar las normas que deberá cumplir Orlando en cada una de las diversas etapas en las que vive y en quién se ha de convertir, ya que anticipar la conducta de las personas, saber cómo van a actuar antes de conocerlas, es la finalidad prioritaria del estereotipo (Cfr. Cook y Cusack, 2010, p. 16). 
La noción de "estereotipo de género" debe entenderse como una "construcción o compresión de los hombres y mujeres en razón de la diferencia entre sus funciones físicas, biológicas, sexuales y sociales. Por tanto su significado es fluido y cambia con el tiempo y a través de la cultura" (Cook y Cusack, 2010, p. 2). El proceso consistente en seleccionar y agrupar a los sujetos de acuerdo a un género y de incorporarlos a un determinado estereotipo empieza, como hemos señalado, muy temprano en la vida del sujeto. Los niños recién nacidos deben ser clasificados según su género; de ahí la importancia de escoger un nombre y un traje adecuados que los denominen y diferencien. Por ejemplo, a los bebés se les viste con colores, telas y estilos que los distingan y anuncien su género a la sociedad. Dichas convenciones son históricas y culturalmente reconocibles. Prueba de ello es que la asociación del rosa para las niñas y el azul para los niños es un hábito relativamente reciente: "A principios del siglo XX, antes de la Primera Guerra Mundial, los niños llevaban rosa ('un color fuerte, más decidido', según la literatura promocional de la época), mientras que las niñas llevaban azul (que se consideraba más 'delicado' y 'remilgado')” (Garber, 1993, p. 1; la traducción es nuestra).

Este deslinde del ser humano en función de lo que cubre su cuerpo resulta insoslayable para "justificar" las divergencias genéricas; sin embargo, la misma dicotomía "masculino"/“femenino", "hombre"/“mujer" es una construcción cultural que, como han debatido el feminismo deconstruccionista y la Queer Theory, se aprende a representar en la cotidianidad, mediante los comportamientos y roles de género:

\footnotetext{
El género no debe considerarse una identidad estable o un sitio donde se funde la capacidad de acción y de donde surjan distintos actos, sino más bien como una identidad débilmente formada en el tiempo, instaurada en un espacio exterior mediante una reiteración estilizada de actos. El efecto del género se crea por medio de la estilización del cuerpo y, por consiguiente, debe entenderse como la manera mundana en que los diferentes tipos de gestos, movimientos y estilos corporales crean la ilusión de un yo con un género constante (Butler, 2007, pp. 273-274; la cursiva es de la autora)
}

Por consiguiente, la asignación del género a temprana edad es decisiva (para esa construcción cultural) en la medida en que moldea al individuo recién nacido según el género que se le asigne.

Ya las aproximaciones construccionistas al tema (Emily Martin, Diana Fuss, Thomas Laqueur...) habían demostrado que el género era producto de los códigos socioculturales prevalecientes. Por añadidura, la moda, lo mismo que el género, también lo es, por lo que constantemente se transforma, cambia y tiende a reutilizar los parámetros de uso de las prendas. El cambio de color para vestir a los neonatos a partir de los años 40 permite entender que la elección de los colores de los ropajes no es exclusiva para un género determinado, sino que depende del constructo cultural aceptado en cada momento y que, por costumbre, se afianzará como norma. "La naturalización del traje, supone una forma 'natural' de vestir, cuando en realidad ningún vestido puede ser 'natural', puesto que su forma siempre es una expresión de la cultura y representa un intento de modificar el cuerpo de alguna manera" (Entwistle, 2002, p. 129). La propia novela de Woolf confirma, ya desde el primer capítulo, que en algunas etapas del pasado han llegado a fusionarse la feminidad y la masculinidad para crear un nuevo estilo híbrido y tal vez genéricamente confuso, vecino a la androginia. Cuando, más adelante, en el capítulo tercero, Orlando se despierta metamorfoseado en mujer, las primeras prendas de las que echará mano para cubrir su anatomía son una de esas casacas y unas bombachas turcas que lo mismo sirven para un sexo que para el otro. Es decir, opta por la fórmula unisex.

A partir de las teorías de Butler, el ideal del género como construcción cultural se empieza a sustentar en la realización de lo que la estudiosa norteamericana llama "actos 
performativos", "donde performativo indica una construcción contingente y dramática del significado" (2007, p. 271). Dicha definición convierte al género como un constructo que está en constante proceso de transformación a través de las distintas épocas y que se institucionaliza de acuerdo con los códigos culturales imperantes en una sociedad dada mediante sucesivos actos cotidianos.

A partir de las premisas de la teoría queer y posfeminista sobre el género, podemos afirmar entonces que la moda, en tanto que construcción cultural que apuntala o reformula la identidad genérica, se basa igualmente en actos performativos: "la comprensión de la performatividad, no como el acto mediante el cual un sujeto da vida a lo que nombra, sino, antes bien, como ese poder reiterativo del discurso para producir los fenómenos que regula e impone" (Butler, 2002, p. 19). De acuerdo con Butler, la performatividad se traduce en la realización de acciones repetitivas como caminar, hablar, la asunción de posturas discursivas, ademanes y movimientos corporales que producen unos efectos que ayudan a regular la percepción de lo que es un hombre y una mujer. La performatividad contribuye a que se cumplan y establezcan los patrones requeridos para las conductas asignadas a mujeres y hombres (Cfr. Frye-Córdoba y Rodríguez-Hillón, 2014, p. 5).

La novela que nos ocupa -ya lo hemos anunciado al comienzo de este artículo- es narrada por un biógrafo, personaje que representa la veracidad y la tradición, porque su relato "intenta" ser imparcial, riguroso y objetivo, meta que en este caso no consigue por completo. El narrador de Orlando es, en cierta medida, una voz disfrazada de la de Virginia Woolf, que en momentos puntuales reflexiona sobre el género y critica la problemática de los sexos y su indefinición. La voz del biógrafo acompaña al protagonista o a la protagonista, con los que también en más de un aspecto se fusiona Woolf, y comenta su andadura a lo largo de toda la novela; sin embargo, tras mutar Orlando de sexo a mitad de la obra, el biógrafo, al querer esclarecer lo sucedido, queda en una posición de desconcierto, evitando ahondar en el asunto del cambio de sexo del personaje, seguramente al comprender que, al no ser ya hombre sino mujer, tal vez no valiese la pena componer su biografía.

Posteriormente, una vez Lady Orlando retorna en un barco desde Turquía a su país de origen (Inglaterra) y medita sobre su ambigüedad, el biógrafo manifiesta sentirse perplejo e intenta asimilar las experiencias y los continuos cambios de género del personaje a partir de sus acciones y su performatividad:

For it was this mixture in her of man and woman, one being uppermost and then the other, that often gave her conduct an unexpected turn. The curious of her own sex would argue, for example, if Orlando was a woman, how did she never take more than ten minutes to dress? And were not her clothes chosen rather at random, and sometimes worn rather shabby? And then they would say, still, she was none of the formality of a man, or a man's love of power. She is excessively tender-hearted. She could not endure to see a donkey beaten or a kitten drowned. Yet again, they noted, she detested household matters, was up at dawn and out among the fields in summer before the sun has risen. No farmer knew more about the crops than she did. She could drink with the best and liked games of hazard. She rode well and drove six horses at a gallop over London Bridge. Yet again, though bold and active as a man, it was remarked that sight of another in danger brought on the most womanly palpitations. She would burst into tears on slight provocations. She was unversed in geography, found mathematics intolerable, and held some caprices which are more common among women than men, as for instance that to travel south is to travel downhill. Whether, then, Orlando was most man or woman, it is difficult to say and cannot now be decided (Woolf, 1977, p. 188) ${ }^{3}$

En este pasaje el biógrafo procura clasificar a Orlando insertándolo en una categoría estable y así determinar si es más "hombre" que "mujer", o viceversa. En el siguiente diagrama colocamos en dos columnas los rasgos que distinguirían a los estereotipos (femeninos y masculinos) de género: 


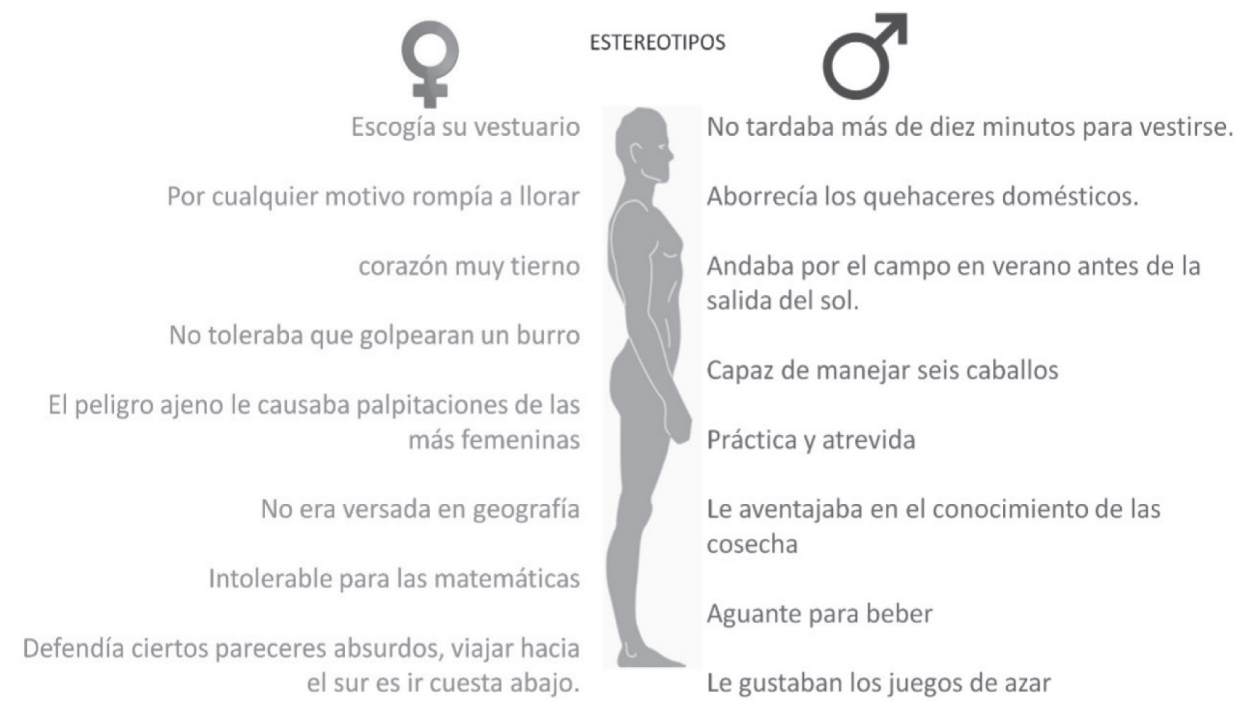

Figura 1. Estereotipos de género a partir de la cita textual en la que el biógrafo analiza la identidad sexual de Orlando

Consciente de hallarse en un callejón sin salida, el biógrafo se da por vencido. En medio de esta resistencia a la teoría, ocurre que Orlando tiene un conocimiento mayor que todos los otros cuerpos vestidos, ya que ha vivido las dos experiencias estereotípicas de género (como hombre y como mujer). Ambas vivencias le permiten reflexionar sobre las convenciones establecidas, criticarlas y jugar con los estereotipos tanto de mujeres como de hombres de su tiempo, aprender a actuar según sus intereses, a respetar ciertas normas o a poner en entredicho los modelos asignados.

Orlando se asemeja a una fuerza motriz que empuja a uno y a otro lado de la oposición binaria de los sexos, oscilando entre las categorías de "hombre" y de "mujer". Esta ambivalencia entre un género y otro le causa estupor al biógrafo, que trata de incluir a Lady Orlando, sin éxito, dentro de una única tipología, mientras que al personaje, en ese momento ya mujer, no le incomoda en absoluto que su rostro y que su identidad permanezcan inalterables. Desde el principio, al descubrirse mujer, cuenta el narrador que las hermosas formas del personaje combinaban la fuerza del hombre y la gracia de la hembra. Características que lo convierten en un ser híbrido que no se ubica en una categoría de género única y restringida, sino que se va reconstruyendo una y otra vez sin necesitar recurrir por defecto a una etiqueta precisa que lo nombre.

El biógrafo decide cerrar sus interrogantes y seguir el periplo de Orlando narrando sus experiencias como si esta cuestión de la indefinición no fuera problemática. Pero sí lo es. La indefinición dentro del cuerpo vestido invita a Orlando a dejar salir sus otros yoes. Lady Orlando entiende que no es suficiente un solo género para su ser, para su personalidad, para sus deseos, para sus exigencias. Su existencia rebosante de autocrítica es más fuerte que las ataduras nobiliarias y que los constructos culturales y sociales adoptados. Mediante sus actos, Orlando manifiesta desinterés por seguir las normas, por aplicarse las categorías rígidas de rol social y de género impuestas. La posibilidad de desahogo que tiene cuando vive durante un intervalo como gitana la llevan a pensar ahora en retornar a ese estado de indefinición que le brindaba ese pueblo que actuaba de espaldas a los convencionalismos sociales, donde 
las libertades de movimientos y el anonimato social la seducían. La trascendencia de la indefinición presupone no solo un cambio de prendas y géneros, sino una condición social muy atrayente que trae consigo reconstrucciones sociales y culturales capaces de desdibujar los límites de la realidad ordinaria.

Lady Orlando, instalada en su mansión, escribe poesía, sabe de caballos, se encarga del cuidado de los animales y de sus negocios, característica que en el siglo XIX solo podía ostentar una mujer socialmente empoderada. Lo mismo que Lady Orlando, había en la época un grupo minoritario de féminas de la alta sociedad que desempeñaba labores diferentes a las destinadas al estereotipo de género femenino. Su número era pequeño, es cierto, y venía favorecido por privilegios de clase y por una envidiable situación económica de la que no gozaba el grueso de la población. Para asumir ciertos conocimientos y destrezas, se debía ser rica, además de rebelde y osada dentro de la encorsetada estructura del patriarcado, como es el caso de Lady Orlando. Así, mientras el biógrafo insiste en querer encasillarla en un género esquemático, la ambiguiedad identitaria del personaje que se impone le aporta un plus de tranquilidad y libertad neutralizante.

Sin embargo, la reflexión en torno a los "disfraces" de Woolf no se detiene en el plano meramente performativo. El biógrafo se apoya en la aparente autoridad de unos "filósofos de los trajes" para esclarecer situación tan peliaguda. El grupo de pensadores que en el capítulo 3 de la ficción teoriza acerca de los trajes se cuela en las reflexiones de la misma Lady Orlando. Estos opinan sobre lo que significa ser mujer y sobre la incertidumbre operada por el cambio de sexo. Los filósofos sostienen la tesis de que "it is clothes that wear us and not we them" (Woolf, 1977, p. 117). ${ }^{4}$ En ese mismo capítulo, Orlando, como mujer, sale a la calle vestida con "the neat black silk knickerbockers of an ordinary nobleman" (Woolf, 1977, p. 116), ${ }^{5}$ irrumpiendo la voz del biógrafo, que anuncia el cambio de apariencia que ha experimentado Lady Orlando:

\footnotetext{
She was becoming a little more modest, as women are, of her brains, and a little more vain, as women are, of her person. Certain susceptibilities were asserting themselves, and others were diminishing. The change of clothes had, some philosopher will say, much to do with it. Vain trifles as they seem, clothes have, they say, more important offices than merely to keep to warm. They change our view of the world and the world's view of us (Woolf, 1977, p. 117) 6
}

Los filósofos explicarían por qué los comportamientos de Orlando como mujer habían cambiado en comparación con los de Lord Orlando, y constatan que, efectivamente, los trajes, no el sexo, eran la causa de esta transformación, manipulando los actos, los sentimientos, el lenguaje y los pensamientos de Orlando cual maniquí trajeado. Las reacciones, los gestos de atención que obtiene en razón de las faldas que lleva puestas y el modo en que responde al tratamiento que le dispensan los hombres, confirman

\footnotetext{
[...] the view that it is clothes that wear us and not we them; we may make them take the mould of arm or breast, but they mould our hearts, our brains, out tongues to their liking. So, having now worn skirts for a considerable time, a certain change was visible in Orlando, which is to be found if the reader will look at page 99, even in her face (Woolf, 1977, p. 117) ${ }^{7}$
}

A partir de esta hipótesis, emergen en la novela preguntas clave para nuestra investigación: ¿por qué los trajes nos usan?; ¿cómo lo hacen? Podríamos responder a estas dudas postulando que los vestidos nos usan porque se trata de prendas y accesorios adaptados a una norma específica de cada época, programados para vestir cierta clase de ser humano, diseñados y puestos en un sistema comercial para moldear cuerpos y actos que reproduzcan roles y categorías de género. La teoría de los trajes como marcadores de género se refuerza al compararse dos retratos de Orlando, uno como hombre y otro como mujer: 
If we compare the picture of Orlando as a man with that of Orlando as a woman we shall see that though both are undoubtedly one and the same person, there are certain changes. The man has his hand free to seize his sword; the woman must use hers to keep the satins from slipping from her shoulders. The man looks the world full in the face, as if it were made for his uses and fashioned to his liking. The woman takes a sidelong glance at it, full of subtlety, even of suspicion. [...] The difference between the sexes is, happily, one of great profundity (Woolf, 1977, p. 117) ${ }^{8}$

A partir de la imagen de estos cuadros se expone y cuestiona la diferencia entre la performatividad de género masculino y la conducta femenina, así como el rol de los trajes dentro de estos modelos. La postura corporal cambia totalmente cuando se llevan faldas y cuando se usan pantalones porque los ademanes y gestualidades son un lenguaje que interviene en la visión de mundo; una propuesta frente a cómo es mirada y cómo él/ella mira y actúa en correspondencia a esa mirada. El hecho de emplear la mano para la guerra y empuñar una espada, o de manejarla para fingir una pose delicada y sostener el vestido, son representaciones fundamentales de las discrepancias entre el rol masculino y el femenino y de las actividades asignadas de acuerdo a cada género.

Los filósofos de la novela proponen que "[h]ad they both worn the same clothes, it is posible that their outlook might have been the same" (Woolf, 1977, p. 117). ${ }^{9}$ Asimismo, opinan que los géneros están mediados por las desemejanzas de los trajes; por consiguiente, una forma de conseguir esa igualdad utópica sería abolir las divisiones sexistas de las vestiduras y, en consecuencia, de los comportamientos y discursos normativos. Aun así, el biógrafo no lo ve posible, pues, para él, el traje revela el dualismo de los sexos, aunque en verdad el sexo sí goza del don de la transitividad:

For here again, we come to a dilemma. Different though the sexes are, they intermix. In every human being a vacillation from one sex to the other take place, and often it is only the clothes that keep the male or female likeness, while underneath the sex is the very opposite of what it is above (Woolf, 1977, p. 118) ${ }^{10}$

Orlando se desplaza de un género a otro, aunque su estrategia sea aparentar uno predeterminado y sus comportamientos se rijan de acuerdo al elegido en cada momento. Esta práctica le permite moverse social y económicamente. A pesar de ese empeño, y como indica la misma voz narradora, los sexos "se confunden" y su estado resulta, en última instancia, indeterminado.

La voz de Woolf, enmascarada tras la opinión de los filósofos, es un instrumento que la novelista articula para discutir de manera crítica cómo a través de los trajes se instala ya un cierto estereotipo de género en la sociedad. A través de la ficción y la creación de los personajes principales y secundarios, Woolf nos conduce a profundas disquisiciones acerca de la performatividad de los actos cotidianos. Podría decirse que, sin la aparición de los filósofos en el relato, la importancia de los trajes no se hubiese notado de manera tan contundente, ni el papel que desempeñan esas prendas en el contexto general de la obra.

\section{El travestismo femenino, una práctica de Lady Orlando en tres pasos: desvestimiento, investimiento y revestimiento}

Los experimentos de Lady Orlando con las vestiduras y con los binarismos de género desembocan en actos de travestismo que se desenvuelven a lo largo de un proceso cuyo primer paso llamaremos desvestimiento y que consiste en despojarse de las cargas significativas asignadas al género femenino y que suponen un lastre. Dicho lastre es el motivo por el cual la protagonista empieza a cambiar de ropa. En el capítulo cuarto el cuerpo vestido de Lady 
Orlando se desviste, empezando por las faldas y los faldones, que le enredan las piernas, y continuando con el calzón. Los nudos que aprietan el miriñaque están rígidos. Ella hala con fuerza y finalmente el corsé cede.

Después acontece la segunda etapa de la performatividad, que denominaremos investimiento y que se resuelve en la asignación de gestos, palabras, modales y comportamientos típicos del género masculino, es decir, nos adentramos en la actuación de género. La separación de los códigos que históricamente han sido adjudicados a la mujer y al hombre como parte de una tradición culturalmente aprendida ha prevalecido en el dominio público y privado a través de mecanismos tales como la educación, la censura y el control de la sociedad. Revelándose contra ellos, Lady Orlando -antes Lord Orlando- mezcla los estereotipos de género en un todo armónico que conforma ese nuevo ser construido. No se queda en ningún extremo; ni hombre, ni mujer, ni femenino, ni masculino: simplemente se ubica en el limbo de los géneros, en la indefinición como posibilidad y en la estrategia de supervivencia para disfrutar por igual de uno y otro sexo.

Seguidamente aparece la etapa del revestimiento, por la cual Lady Orlando reconstruye su género portando prendas consideradas masculinas que le sirven para alterar su forma de actuar y mostrarse en la sociedad. Lady Orlando se mira frente al espejo del armario. Ningún sexo le interesa. Ninguna prenda es tan hermosa como para decorar sus deliciosas extremidades; así que las fusiona y alcanza la simbiosis perfecta. La belleza y la fuerza la acompañan en ese trance decisivo en el que, por añadidura, consigue compatibilizar la gallardía y la delicadeza, la ternura y la dureza, los gritos y las lágrimas. Ella deviene así una amalgama de cualidades antitéticas.

Orlando transforma la imagen corporal a través del cambio de prendas, modificándose y posibilitando una ruptura con la norma heterosexual (se sugiere que tiene más de una aventura lésbica). Dichos trasvases, insistimos, confirman que "el travestismo es un ejemplo de performatividad, [que] se distancia del canon jurídico del discurso productor de los cuerpos sexuados" (Gutiérrez, 2013, p. 69). En concordancia con ello, Lady Orlando, al alejarse de los estereotipos establecidos por decreto, transgrede la normatividad. El cuerpo se desviste y se inviste de nuevos significados. La anatomía del sexo es relegada por el poder transgresor de aquellas prendas que se salen de lo normal. Entonces, cuando se traviste e imita el género hegemónico masculino, socaba hipotéticamente las normas. Acto en el que Butler vería un desafío a "la pretensión a la naturalidad y [a la] originalidad de la heterosexualidad" (2002, p. 185).

\section{El Archiduque travesti}

En Orlando su protagonista no es el único personaje que se decanta por el travestismo, no obstante ser descubierto tardíamente por Orlando. El enamoramiento del Archiduque Harry le lleva a cambiar su traje y, para lograr su cometido, se disfraza de mujer, asecha y acosa a quien por entonces era un hombre.

El Archiduque travesti aparece en la novela en el capítulo cuarto cuando Orlando regresa de la meseta central de Anatolia convertida en una dama dieciochesca. Lady Orlando, a pesar de los litigios en su contra por su cambio de sexo, podía vivir en su mansión. En aquel momento aparece la Archiduquesa Harriet, mujer que le había hecho huir de Inglaterra a causa del atosigamiento amoroso al que lo sometía cuando era un hombre. De nuevo regresa transformada en mujer y no puede evitarla. Acto seguido la invita a seguir y le brinda una copa. 
De un momento a otro aparece en su lugar un hombre alto de ropaje negro y con los atuendos de mujer en el guardafuego. En realidad, la Archiduquesa era el Archiduque, quien se había disfrazado de mujer para cortejar a Orlando en el siglo XVII. Ahora que su pretendido ha cambiado de sexo y que se encuentra en el siglo XVIII, ella retorna bajo su verdadera identidad masculina:

\footnotetext{
She was alone with a man.

Recalled thus suddenly to a consciousness of her sex, which she had completely forgotten, and of his, which was now remote enough to be equally upsetting. Orlando felt seized with faintness.

'La!,' he cried, putting her hand to her side, 'how you frighten me!'.

"Gentle creature,' cried the Archduchess, falling on one knee and at the same time pressing a cordial to Orlando's lips, 'forgive me for the deceit I have practiced on you!'

Orlando sipped the wine and the Archduke knelt and kissed her hand.

In short, the acted the parts of man and woman for ten minutes with great vigour and then fell into natural discourse. The Archduchess (but she must in future be known as the Archduke) told his story - that he was a man and always had been one; that he had seen a portrait of Orlando and fallen hopelessly in love with him; that to compass his ends, he had dressed as a woman and lodges at the Baker's shop; that he was desolated when he fled to Turkey; that he had heard of her change and hastened to offer his services (here he teed and heed intolerably). For to him, said the Archduke Harry, she was and would ever be the Pink, the Pearl, the Perfection of her sex (Woolf, 1977, pp. 111-112) ${ }^{11}$
}

El móvil de la tentativa travestista del Archiduque es en ese momento de carácter estratégico y homosexual, porque busca enamorar a Orlando sin importarle que sea de su mismo sexo. Ahora bien, aunque Orlando se haya convertido en mujer, sus sentimientos permanecen intactos; su comportamiento revela el egoísmo típicamente masculino que ha sido una de las marcas distintivas de este género. En cualquier sociedad patriarcal son las mujeres las que han de seguir a los hombres hasta el fin del mundo, si es necesario, aun cuando ellos no se hayan enamorado de una mujer real sino de la imagen grabada o inscrita en un retrato. Woolf, en este episodio, alude a la costumbre masculina que había entre los nobles y la realeza de evaluar retratos de posibles candidatas para el matrimonio y así afianzar alianzas políticas y económicas sin contar con la anuencia de la mujer elegida.

Durante esta confesión del Archiduque, quien además pone a disposición de Lady Orlando su fortuna y sus ducados, el noble derrama unas lágrimas que no puede contener. Al verlo llorar, Lady Orlando se escandaliza porque sabe, como mujer, que debe comportarse así cuando un hombre se emociona ante alguien de su sexo.

Después de esta secuencia, el Archiduque sigue persiguiendo y cortejando a Lady Orlando por bastante tiempo. Ella le recibe en su casa, pero evade el tema del compromiso y le inventa un juego que se llama "Fly Loo" ["mosca Asentada"], consistente en atrapar la mayor cantidad de moscas posible en un cubo de azúcar. Lady Orlando se vuelve experta en esta distracción que busca mantener a su pretendiente ocupado, hasta que un día, cansada del constante asedio, le hace trampa. Este se enoja y Lady Orlando también se enfada; el Archiduque, con su insistencia, revela su incapacidad para entender que no le interesa seguir la costumbre y comprometerse.

Lady Orlando sale de su mansión vestida con bombachas de seda y se dirige a la ciudad montada en sus seis caballos al galope. Con este cambio de prendas, Lady Orlando deja atrás los trajes femeninos asignados que mantenían su apariencia de dama. Como señalamos a propósito del primer capítulo, en este instante Lady Orlando toma una sólida determinación frente a los trajes que usa y las opciones que requiere frente a la sociedad que la vigila. El vestirse de un determinado género se convierte en una operación voluntaria y no en un imperativo para Orlando. Téngase en cuenta que por entonces Lady Orlando aún no se 
ha disfrazado, pero sí se despoja de los vestidos y sale con una prenda unisex como son las bombachas de seda. Esta decisión de salir con prendas diferentes a las de su sexo le lleva a pensar que, si regresa a su armario, con sus antiguas prendas, tendrá otras alternativas que antes, cuando era hombre, eran consideradas "naturales". Podría pensarse que llega a esta conclusión después de haber reevaluado su vida como hombre-mujer y después de interpretar el travestismo del Archiduque como un detonador de sus propios actos de travestismo.

El Archiduque decide travestirse como un gesto personal "de autoconstruirse a voluntad o de ocultarse bajo una forma otra, difuminando las líneas del disfraz y del aspecto, aceptado como natural. De esta forma, apunta hacia el estado inestable, convencional y manipulable hasta el que descienden las señas identitarias" del personaje (Gutiérrez, 2013, p. 65). El Archiduque logra timar con tal eficacia a Orlando que este no llega a la certeza de la real identidad del Archiduque sino a su regreso como mujer, cuando recibe la confesión. Se trata de una ruptura de la estructura establecida donde se privilegia la apariencia del sujeto en la sociedad. El Archiduque, a pesar de resultar molesto para Orlando, ejerce de revulsivo y de guía que encamina a Lady Orlando a través de sus diferentes movimientos travestistas, instándola a que reconsidere su actual apariencia externa para agenciarse de una identidad fluida.

\section{El travestismo de Orlando: la apertura del armario}

Después del incidente con las bombachas de seda, que es posterior a su relación con el Archiduque, Lady Orlando se encuentra en medio de una reunión literaria con altos intelectuales y nobles, entre ellos Lord Chesterfield, quien en voz baja le confía a un hijo suyo el siguiente secreto:

\footnotetext{
'Women are but children of a larger growth... A man of sense only trifles with them, plays with them, humours and flatters them', which, since children always hear what they are not meant to, and sometime, even, grow up, may have somehow leaked out, so that the whole ceremony of pouring out tea is a curious one. A woman knows very well that, though a wit sends her his poems, praises her judgment, solicits her criticism, and drinks her tea, this by no means signifies that he respects her opinions, admires her understanding, or will refuse, though the rapier is denied him, to run her through the body with his pen (Woolf, 1977, p. 133) $)^{12}$
}

Esta alusión despectiva, denigrante y discriminadora hacia la mujer sofoca a Lady Orlando, porque las menciones a su propio sexo la limitan; además, los asistentes desacreditan su labor de escritora. Semejantes menosprecios a su condición femenina y de escritora la convierten en un sujeto que se ha concienciado de su situación de desventaja en la sociedad y de la necesidad de cambiar de traje para cambiar de género y obtener respeto.

Poco antes de eso a Lady Orlando le notifican varios procesos legales en su contra por el hecho de ser mujer, aclarándosele que el deber de una fémina era casarse para poder heredar. Contratiempos que indican que la mujer, y en este caso Lady Orlando, no era sujeto de pleno derecho. Después de participar en reuniones sociales, advierte que por su género se ve relegada a servir el té y a permanecer en silencio. Para seguir su vida activa de negocios, para poder opinar en público y para continuar administrando los bienes que aún no le habían confiscado, necesita acudir a un remedio: el cambio de prendas. Es por ello por lo que Lady Orlando sale de la habitación, ofuscada, y acude a su armario, iniciándose la etapa que hemos llamado más arriba "de desvestimiento". Las puertas del guardarropa se abren de par en par para brindarle las prendas masculinas que usaba cuando era hombre y que había conservado en secreto.

Apenas saca a la luz el contenido del ropero, los trajes de épocas pasadas se despiertan. Orlando los inspecciona con malicia, con rechazo y admiración. Los trajes de Lord se han 
modificado con las décadas, pero aún siguen en perfecto estado, aunque pasados de moda. Lady Orlando, en esta fase posterior de investimiento, se cubre primero con las bombachas de seda, después con el chaleco color vino, luego con el jubón y finalmente con las botas. Una vez vestida, se mira al espejo y observa que en nada ha cambiado. Un gesto transgenérico que realiza en privado, ya que sabe que está prohibido.

Orlando opta por volver a sus trajes de Lord y llevar las prendas masculinas, de modo que comprueba que le quedan iguales que cuando era un hombre. También comprueba que al usar este tipo de indumentaria, recobra la credibilidad de ser un legítimo varón. Después de salir a las calles londinenses, Orlando, vestido como Lord, se encuentra en el parque con una mujer, a la cual decide seducir. Lady Orlando descubre que puede cortejar de nuevo a las de su mismo sexo. Pero lo que hará en realidad será analizar su comportamiento, ya que esta mujer que acaba de conocer finge también su rol femenino.

\begin{abstract}
Then she rose, turned, and went into the house, where she sought her bedroom ad locked the door. Now she opened a cupboard in which hung still many of the clothes she had worn as a young man of fashion, and from among them she chose a black velvet suit richly trimmed with Venetian lace. It was a little out of fashion, indeed, but it fitted her to perfection and dressed in it she looked the very figure of a noble Lord. She took a turn or two before the mirror to make sure that her petticoats had not lost her the freedom of her legs, and then let herself secretly out of doors (Woolf, 1977, p. 134) ) $^{13}$
\end{abstract}

La vestidura se modifica y los roles también, y Lady Orlando, al acudir a su fondo de armario, se encuentra con sus otras pieles. Al revestirlas, se vuelve otra vez un caballero; luego será de nuevo una dama; después, se desviste y se convertirá en un ser indefinido, pero casi libre. De este modo, la persona se arropa con nuevos gestos, nuevas concepciones y palabras que alimentan esa reconstrucción de las posibles elucubraciones críticas frente a los géneros asumidos. Todas esas pieles que la/o cubren, juntas, constituyen una sola. Caminará a partir de ahora por las calles con una seguridad casi olvidada. La realidad de Lady Orlando se resquebraja y se desmiembra, pues las mudanzas de ropas evaporan su antigua realidad en el momento en que Lady Orlando, dentro del guardarropa, calibra su figura. Su armario no consta de cajones porque la encasillarían, mas se presenta como un maniquí con piezas móviles que da cuenta de su género para luego desdibujarlo y rearmarlo según sus necesidades y su conveniencia. Culmina de esta guisa el proceso de revestimiento.

En suma, si los cuerpos travestidos se muestran como anómalos frente al modus operandi convencional, en tanto que generan dudas sobre su representación y su presencia en un espacio discursivo dado, ponen en evidencia también la conflictiva relación entre travestismo y realidad, puesto que el cambio de prendas no es un hecho banal e insignificante, sino que lleva impresa toda la carga simbólica de la herida profunda y sangrante de las estructuras sociales y culturales que lo rodean. Butler considera que el travestismo "[e]s un ejemplo que tiene por objeto establecer que la 'realidad' no es tan rígida como creemos", y en su ensayo El género en disputa propone específicamente "exponer lo tenue de la 'realidad' del género para contrarrestar la violencia que ejercen las normas de género" (2007, p. 29).

Orlando aprende a mantener intacta esa dualidad, lo que le sirve para sustituir un género por otro al tiempo que se cambia de traje: "She had, it seems, no difficulty in sustaining the different parts, for her sex changed far more frequently than those who have worn only one set of clothing can conceive" (Woolf, 1977, pp. 137-138). ${ }^{14}$ Lady Orlando fluctúa entre los géneros según las circunstancias, a su antojo; y, de hecho, "she reaped a twofold harvest by this device; the pleasures of life were increased and its experiences multiplied" (Woolf, 1977, p. 138). ${ }^{15}$ Este descubrimiento que hace Lady Orlando de las arbitrariedades implícitas en las 
categorías de género la adentra en un juego beneficioso consistente en invertir los imaginarios culturales creando la proyección de un estereotipo de género falsa, tan falsa como la que se considera real. El travestismo, insistamos, es un artificio que desmonta la creencia de que el género es natural y "problematiza la noción de binariedad, cuestionándose una nitidez prediscursiva que está reñida con las fronteras indeterminadas que han dividido categorías, de por sí inestables, como son las de lo masculino y lo femenino" (Gutiérrez, 2013, p. 71; la cursiva es del autor).

Lady Orlando viene de travestirse y de ubicarse clandestinamente en la sociedad de las mujeres; inclusive escribe poesía que ella misma atribuye a un Lord que podría ser primo suyo, pero que realmente era Lady Orlando. Esta suplantación de la autoría literaria por parte de escritoras era común en el siglo XIX, donde las mujeres usaban seudónimos masculinos para poder publicar sus obras y recibir comentarios serios. En este caso Lady Orlando, al hacerse pasar por hombre, decía que él era un primo de Lady Orlando, incurriendo en una clase de travestismo que se podría calificar de "estratégico" ya que, si emplea un álter ego masculino, es solo para poder dar a conocer su creación.

\section{Conclusiones}

Orlando es un aristócrata que aparentemente cumple con las normas de clase del momento; sin embargo, trasgrede los códigos establecidos cuando decide incursionar en la literatura. Además, se relaciona con poetas plebeyos y tiene amores con plebeyas (vestido con un traje diferente a su rol). Después del cambio de sexo y de profundas reflexiones sobre las indumentarias, también cambia de género (vestido con un traje diferente, descoloca su nuevo género femenino).

Nuestra aproximación a la novela de Woolf y al concepto de performatividad de género nos ha permitido entender que la realidad no es estática, sino que se moldea culturalmente y así se refleja en la sociedad y en la misma obra de la escritora inglesa. De esta manera el personaje de Orlando, con el cambio de prendas y de trajes, no solo modifica sus comportamientos como ente ficcional que es, sino que también transforma el devenir de realidades opresivas en la existencia humana.

Desmontar la realidad rígida que ofrece una época es un valor agregado de esta obra por la que discurren varios Orlandos, varios cuerpos dentro de uno solo, con distintas pieles. Orlando es múltiple y a la vez es el/la mismo/a. Esta posibilidad la descubre y redescubre el personaje cuando vive como hombre y como mujer sucesivamente. También cuando experimenta el amor con las personas de su mismo sexo. Inclusive se propone la hipótesis de su no pertenencia a un estereotipo en particular, adoptando una hibridez y una diversidad que escamotean cualquier intento de definición precisa.

La novela de Woolf ayuda a comprender cómo el traje legitima los cuerpos, cómo los jerarquiza en la sociedad y los define. Orlando se desviste, se inviste y se reviste con prendas textiles que dan cuenta de las cargas significativas que lo/la nombran como hombre/ mujer, como inglés/inglesa, como gitana/aristócrata, como Lord/Lady, como poeta, abogado, cortesano, amante, esposa y escritora. Los trajes de Orlando iluminan vertientes de la moda concebida como un conglomerado de cuerpos (trans)vestidos que forman parte del inventario sociocultural de cada época y de la construcción subjetiva del sujeto. Es notorio que el hombre de los siglos XIX y XX renunció en gran parte a los adornos aparatosos. En contraposición, 
la moda imperante en los siglos XVI y XVII mostró que la exhibición y la vanidad no eran experiencias exclusivas de las mujeres, sino que también se daban en los hombres, que se adornaban con llamativas prendas, cintas y brocados. Si analizáramos la cuestión desde una perspectiva histórica, podría verse cómo la moda femenil plantea otro tipo de masculinidad diferente a la tradicional. Esta realidad convencional entrará en crisis a medida que la idea de sujetos fijos y estáticos se tambalea.

En Inglaterra, la ornamentación usada por los varones en los siglos preindustriales será abolida por decreto de la moral victoriana. El régimen victoriano dictaba normas que postulaban cómo debían vestirse y comportarse un hombre y una fémina. Estos constructos culturales que conformarían el estereotipo del hombre y la mujer de esos periodos se materializan en los trajes que viste Orlando y en los actos performativos que lo revisten. Las mujeres en los siglos pretéritos debían llevar ropajes amplios y ostentosos que le cubrieran toda la piel para continuar prolongando la realidad de la mujer como objeto decorativo y víctima de represión. Con el paso del tiempo, al traje de hombre le disminuyen sus telas para recobrar la movilidad física y multidisciplinar, mientras que la mujer seguirá anclada y constreñida por mucho tiempo en la aparatosidad de sus vestidos. Un ejemplo de este encorsetamiento es el miriñaque, una pieza muy usada en el siglo XIX.

De algún modo la autora enmascara su voz a través de las opiniones de los filósofos en la obra, quienes afirman que son los trajes los que nos usan y los que nos hacen pasar de un sexo a otro, en contraposición a la idea preconcebida de la ropa como un instrumento al servicio de los sujetos. Esta afirmación es el detonante que nos ha llevado a pensar en los trajes como pilar y esqueleto del presente artículo. De hecho, ¿quién no se ha sentido alguna vez vestido/a por la ropa, obligado/a a representarse como si fuera un maniquí, en vez de sentir que son los trajes los que verdaderamente nos visten? Esa sensación de subordinación a la ropa, de sometimiento, de control, es la que nos estimuló a contemplar la figura de Orlando como si estuviese armado a partir de diferentes maniquís que se extienden a lo largo de las épocas y captar así, a medida que nos internábamos en la novela, la utopía de devenir un ser distinto.

Objetivamente hablando, no hay trajes de hombres y trajes de mujeres, ni indumentarias femeninas ni masculinas. En realidad, todo forma parte de una construcción cultural, lo que explica que esos hábitos cambien y se reformen según las sociedades y culturas. Teniendo en cuenta esto, dicha configuración puede ser comprendida y eventualmente invertida. Y una manera de generar el cambio de paradigma es por medio de la literatura, un camino imaginativo donde se puede leer desde otro enfoque la realidad y se puede visibilizar las problemáticas de género y la diversidad de sujetos que se desentienden de los estereotipos y roles de género tradicionales.

La taxonomía del género se ha encargado de diferenciar un traje para la mujer y otro para el hombre con el fin de condicionar al sujeto de acuerdo al género. Ahora bien, tal y como explica la teoría posmoderna del género desarrollada por Butler y otras investigadoras, su definición no es natural, por lo que el sujeto se halla inmerso entre las divisiones genéricas y su performatividad. Lady Orlando, a través de su experiencia vital, descubre que la feminidad y la masculinidad son actos simulados y actuados, hallazgo que le servirá para comprender su(s) género(s) y lo artificial de sus sucesivas construcciones.

Orlando acabará aprendiendo a manipular los estereotipos existentes. Cuando tiene lugar su cambio de hombre a mujer, no rechaza su nueva condición, sino que aprende de ella nuevas formas de sentirse persona. Por tanto, la estratagema de Orlando se basa en analizar 
las características y restricciones del nuevo estereotipo según las prescripciones de la época, para luego camuflarse y hacer que ese disfraz forme parte de la norma. No obstante, la culminación de dicha táctica se sintetiza en el cruce de los límites genéricos que llevaría a cabo y en su reconstrucción como un sujeto diferente. Es en estos aspectos señalados donde mejor cabe percibir las conexiones de Orlando con la teoría queer actual.

Así pues, desde la mirada de los actos de travestismo, nuestra lectura de la novela de Woolf nos ha desvelado la idea de la inexistencia de un molde original de género y la posibilidad de la reconstrucción del mismo. El travestismo ha servido de excusa para el desmontaje no solo del concepto de género, sino también como una propuesta de incesantes reconstrucciones que generarían nuevos sujetos válidos. La escritora inglesa reinventa en Orlando al sujeto y provoca que los conceptos culturales tradicionalistas de su país, que miraban a las personas en blanco y negro, negando las medias tintas, se desestabilicen. Por esta razón, en el momento en que diera a conocer su obra, la crítica literaria, todavía mayoritariamente representada por hombres, seguramente no supo captar lo revolucionario de su mensaje, exceptuando tal vez cierto sector del público femenino que, víctima de los prejuicios del sistema, sí se sintió identificado con muchas de las problemáticas y los modelos identitarios que esta ficción bosquejaba.

\section{Notas}

1. Al género de la biografía se dedicaron el propio abuelo de la autora, James Stephen, y su padre, Leslie Stephen. La misma Woolf llegó a cultivarlo publicando en 1940 un libro biográfico sobre Roger Fry, artista y crítico inglés miembro del grupo de Bloomsbury, al que pertenecía la novelista.

2. Idea esta que se desmarca de la opinión más común, según la cual la novela sería una especie de "carta de amor" de Woolf a Vita (Nicolson, 1973, p. 202).

3. "Esa mezcla de hombre y de mujer, la momentánea prevalencia de uno y de otra, solía dar a su conducta un giro inesperado. Por ejemplo, las mujeres curiosas preguntarán: Si Orlando era mujer, ¿cómo no tardaba más de diez minutos para vestirse? ¿Y no estaban sus trajes elegidos a la buena de Dios, y a veces hasta raídos? Sin embargo, le faltaba la gravedad de un hombre, o la codicia de poder que tienen los hombres. Su corazón era muy tierno. No toleraba que golpearan un burro, o ahogaran un gatito. En cambio, aborrecía los quehaceres domésticos, se levantaba al alba y andaba por el campo en verano antes de la salida del sol. Ningún agricultor la aventajaba en el conocimiento de las cosechas. Era de mucho aguante para beber y le gustaban los juegos de azar. Montaba bien y era capaz de manejar seis caballos al galope sobre el Puente de Londres. Sin embargo, aunque era tan práctica y atrevida como un hombre, la vista del peligro ajeno le causaba palpitaciones de las más femeninas. Por cualquier motivo rompía a llorar. No era versada en geografía, juzgaba intolerables las matemáticas y defendía ciertos pareceres absurdos, que abundan más entre las mujeres que entre los hombres; por ejemplo, que viajar hacia el sur es ir cuesta abajo. Imposible resolver por ahora si Orlando era más hombre o más mujer" (Woolf, 1983, pp. 123-124).

4. "son los trajes los que nos usan, y no nosotros los que usamos los trajes" (Woolf, 1983, pp. 122-123).

5. "bombachas de seda negra como un gentilhombre cualquiera" (Woolf, 1983, p. 122).

6. "Se estaba poniendo algo más modesta, como la mayoría de las mujeres, de su inteligencia; un poco más vanidosa, como la mayoría de las mujeres, de su persona. Ciertas sensibilidades aumentaban, otras disminuían. // Algunos filósofos dirán que el cambio de traje tenía buena parte en ello. Esos filósofos sostienen que los trajes, aunque parezcan frivolidades, tienen un papel más importante que el de cubrirnos. Cambian nuestra visión del mundo y la visión que tiene de nosotros el mundo" (Woolf, 1983, p. 122).

7. "la tesis de que son los trajes los que nos usan, y no nosotros los que usamos los trajes: podemos imponerles la forma de nuestro brazo o de nuestro pecho, pero ellos forman a su antojo nuestros corazones, nuestras lenguas, nuestros cerebros. A fuerza de usar faldas por tanto tiempo, ya un cierto cambio era visible en Orlando; un cambio hasta de cara, como lo puede comprobar el lector en la galería 
de retratos" (Woolf, 1983, pp. 122-123). En la cita en inglés se remite a la página 99, donde aparecía una de las fotos que le hizo el fotógrafo Lenare a Vita para ilustrar la primera edición de la novela. En todas ellas se podía ver a la amiga de Woolf caracterizada como Orlando en las distintas fases de su vida.

8. "Si comparamos el retrato de Orlando hombre con el de Orlando mujer, veremos que aunque los dos son indudablemente una y la misma persona, hay ciertos cambios. El hombre tiene libre la mano para empuñar la espada, la mujer debe usarla para retener las sedas sobre sus hombros. El hombre mira el mundo de frente como si fuera hecho para su uso particular y arreglado a sus gustos. La mujer lo mira de reojo, llena de sutileza, llena de cavilaciones tal vez. [...] Afortunadamente, la diferencia de los dos sexos es más profunda" (Woolf, 1983, p. 123).

9. "si hubieran usado trajes iguales, no es imposible que su punto de vista hubiera sido igual" (Woolf, 1983, p. 123).

10. "De nuevo nos encontramos ante un dilema. Por diversos que sean los sexos, se confunden. No hay ser humano que no oscile de un sexo a otro, y a menudo solo los trajes siguen siendo varones o mujeres, mientras que el sexo oculto es lo contrario del que está a la vista" (Woolf, 1983, p. 123).

11. "Orlando estaba sola con un hombre. // Bruscamente consciente de su propio sexo, que había olvidado por completo, y del sexo del otro, ahora lo bastante remoto, para inquietarla por igual, Orlando se sintió desvanecer. // ‘iAy!', exclamó, llevándose la mano al costado, ‘iqué miedo!'. // 'Suave criatura', gritó la Archiduquesa, doblando una rodilla y aproximando, al mismo tiempo, un cordial a los labios de Orlando, 'perdóneme este engaño'. // Orlando tomó el vino a traguitos y el Archiduque se arrodilló y le besó la mano. // En resumen, hicieron su papel de hombre y mujer durante diez minutos y luego se pusieron a charlar con naturalidad. // La Archiduquesa (de ahora en adelante le diremos el Archiduque) relató su historia: que era, y siempre había sido, un hombre; que se había enamorado locamente de un retrato de Orlando; que para lograr su propósito se había disfrazado de mujer y se había alojado en la Panadería; que se desesperó cuando supo su viaje a Constantinopla; que le habían comunicado su cambio y venía a ponerse a sus órdenes (aquí se puso a cacarear intolerablemente). Porque para él, dijo el Archiduque Enrique, ella era y siempre sería el Primor, la Perla, la Perfección de su sexo" (Woolf, 1983, p. 117).

12. "Las mujeres no son más que niños grandes... El hombre inteligente solo se distrae con ellas, juega con ellas, procura no contradecirlas y las adula'. Como los niños invariablemente oyen lo que no deben y a veces llegan a ser grandes, el secreto se ha divulgado y la ceremonia de servir el té es curiosísima. // Una mujer sabe muy bien que por más que un escritor le envíe sus poemas, elogie su criterio, solicite su opinión y beba su té, eso no quiere absolutamente decir que respete sus juicios, admire su entendimiento, o dejará, aunque le esté negado el acero, de traspasarla con su pluma" (Woolf, 1983, p. 138).

13. "Entonces se levantó y regresó a la casa, donde fue derecho a su cuarto y se encerró con llave. Abrió un armario donde estaban los trajes que había usado cuando era un gentilhombre, y eligió un traje negro de terciopelo con adornos de encaje de Venecia. En verdad, estaba un poco pasado de moda, pero le quedaba como un guante, y la hacía parecer el prototipo de un noble Lord. Dio un par de vueltas ante el espejo para cerciorarse de que las faldas no le habían hecho perder la soltura de las piernas, y salió secretamente a la calle" (Woolf, 1983, p. 139).

14. "Parece que no le costaba el menor esfuerzo mantener ese doble papel, pues cambiaba de género con una frecuencia increíble para quienes están limitados a una sola clase de trajes” (Woolf, 1983, p. 142).

15. "Ese artificio le permitía recoger una doble cosecha, aumentaron los goces de la vida y se multiplicaron sus experiencias. Cambiaba la honestidad del calzón corto por el encanto de la falda y gozaba por igual del amor de ambos sexos" (Woolf, 1983, p. 142).

\title{
Bibliografía
}

Barr, M. S. y Feldstein, R. (Eds.). (1989). Discontented Discourses: Feminism/Textual Intervention/Psycoanalysis. Urbana/Chicago: University of Illinois Press.

\author{
Bazin, N. T. (1973). Virginia Woolf and Androginous Vision. New Brunswick: Rutgers \\ University Press.
}


Burn, C. L. (1994). Re-dressing Feminist Identities: Tensions between Essential and Constructed Selves in Virginia Woolf's Orlando. Twentieth Century Literature. 40 (3), 342-364.

Butler, J. (2002). Cuerpos que importan. Sobre los límites materiales y discursivos del "sexo". (A. Bixio, tr.). Buenos Aires: Editorial Paidós SAICF.

Butler, J. (2007). El género en disputa. El feminismo y la subversión de la identidad. (M. A. Muñoz, tr.). Barcelona: Editorial Paidós Ibérica.

Caughie, P. (1989). Virginia Woolf's Double Discourse. Por Barr y Feldstein (Eds.). Discontented Discourses: Feminism/Textual Intervention/Psycoanalysis. (40-53). Urbana/Chicago: University of Illinois Press.

Cervetti, N. (1996). In the Breeches, Petticoats, and Pleasures of Orlando. Journal of Modern Literature. 20 (2), 165-175.

Cook, R. J. y Cusack, S. (2010). Estereotipos de género. Perspectivas legales trasnacionales. (A. Parra, tr.). Bogotá: Profamilia. http://www.villaverde.com.ar/es/assets/investigacion/ violencia-genero/estereotipos-genero-cook.pdf. [Consulta 20 de marzo de 2016].

Cruz de Amenábar, I. (1996). El traje. Transformaciones de una segunda piel. Santiago de Chile: Ediciones Universidad Católica de Chile.

Diego, R. y Vázquez, L. (2002a). Orlando. Por Diego y Vázquez (200b). Figuras de mujer. (103119). Madrid: Alianza Editorial.

Diego, R. y Vázquez, L. (2002b). Figuras de mujer. Madrid: Alianza Editorial.

Entwistle, J. (2002). El cuerpo y la moda. Una visión sociológica. (A. Sánchez Mollet, tr.). Barcelona: Ediciones Paidós Ibérica.

Farwell, M. R. (1975). Virginia Woolf and Androgyny. Contemporary Literature. 16 (4), 433-451.

Frye-Córdoba, M. P. y Vicente-Rodríguez Hillón, D. (2014). Tres actos de moda en el armario de Orlando. Quaestiones Disputatae. 15 (15), 113-123. http://revistas.ustatunja.edu.co/ index.php/qdisputatae/article/view/846/819. [Consulta 20 de marzo de 2016].

Gans, T. (2011). Gender and Unity of the Self in Virginia Woolf's Orlando. Student Pulse. 3 (5), 22 párrs. http://www.studentpulse.com/articles/523/gender-and-unity-of-the-selfin-virgina-woolfs-orlando. [Consulta 14 de abril de 2016].

Garber, M. (1993). Vested Interests. Cross-Dressing \& Cultural Anxiety. Nueva York: HarperPerennial.

Gascón-Vera, E. (2002). To Be or Not to Be: la ansiedad de la androginia en Virginia Woolf. Clepsydra. 1, 99-110.

Gutiérrez, J. I. (2013). Del travestismo femenino. Realidad social y ficciones literarias de una impostura. Vigo: Editorial Academia del Hispanismo.

Lippmann, W. (1964). La opinión pública. (S. Molloy, tr.). Buenos Aires. Fabril Editora.

Marcus, J. (1987). Virginia Woolf and the Languages of Patriarchy. Bloomington: Indiana University Press.

McNamara, S. (2011). Seducción y venganza en 'Orlando' de Virginia Woolf. Aperturas Psicoanalíticas. 39. http://www.aperturas.org/articulos.php?id=0000724. [Consulta 20 de marzo de 2016]. 
Nicolson, N. (1973). Portrait of a Marriage: Vita Sackville-West and Harold Nicolson. Nueva York: Atheneum.

Roe, S. (1990). Writing and Gender: Virginia Woolf's Writing Practice. Hemel Hempstead/ Nueva York: Harvester Wheatsheaf/St. Martin Press.

Sánchez-Pardo González, E. (2004). 'What Phantasmagoria the Mind Is': Reading Virginia Woolf's Parody of Gender. Atlantis. 26 (2), 75-86. http://www.atlantisjournal.org/old/ Papers/26_2/075-086\%20S\%C3\%A1nchez-Pardo.pdf. [Consulta 19 de abril de 2016].

Sanyal, S. (2014). Breaking through the Limits of Flesh: Gender Fluidity and (Un)natural Sexuality in Virginia Woolf's Orlando. Rupkatha Journal on Interdisciplinary Studies in Humanities. 6 (1), 79-86. http://rupkatha.com/V6/n1/08_Virginia_Woolf_Orlando. pdf [Consulta 10 de mayo de 2016].

Showalter, E. (1977a). Virginia Woolf and the Flight into Androgyny. A Literature of Their Own: British Women Novelist from Brontë to Lessing. (263-297). Princeton: Princeton University Press.

Showalter, E. (1977b). A Literature of Their Own: British Women Novelist from Brontë to Lessing. Princeton: Princeton University Press.

Woolf, V. (1977). Orlando. A Biography. Londres: Grafton Books.

Woolf, V. (1980). Diarios: 1925-1930. (A. Olivier Bell, Ed.). (M. de Juan, tr.). Madrid: Ediciones Siruela.

Woolf, V. (1983). Orlando. (J. L. Borges, tr.). México D. F.: Editorial Hermes.

Zambrini, L. (2009). Prácticas del vestir y cambio social. La moda como discurso. Questión. 24. http://perio.unlp.edu.ar/ojs/index.php/question/article/view/860/761 [Consulta 2 de septiembre de 2016]. 
